\title{
Uma proposta interdisciplinar entre Literatura, Linguística e Ensino
}

\author{
Lilian Barros de Abreu SILVA (D) \\ Universidade de São Paulo (USP)
}

RESUMO

Esta resenha apresenta discussões desenvolvidas no evento Abralin ao Vivo, durante a conferência Literatura, Linguística e Ensino, proferida pela professora Marisa Lajolo. Ela articulou dados recentes do PISA sobre os níveis de leitura no país com textos midiáticos que mostram valores sociais do século XIX para mostrar que os problemas nesse âmbito não são recentes. Além disso, a professora fez reflexões importantes sobre as práticas atuais de leitura, o que se ensina nos cursos de Letras e o que se aprende nas aulas de linguagens do ensino básico para, por fim, apresentar sua proposta interdisciplinar. Desse modo, a integração entre as pesquisas em estudos linguísticos e literários e a prática docente pode contribuir para um saber efetivo e crítico.

\section{ABSTRACT}

This review presents discussions developed at Abralin ao Vivo event, during the live Literature, Linguistics and Teaching, made by Professor Marisa Lajolo. She articulated recent PISA data on reading levels in Brazil with media texts that show 19th century social values to present that the problems in this area are not recent. In addition, the Professor made important reflections on current reading practices, what is taught in Literature courses and what is learned in basic language classes to, finally, present her interdisciplinary proposal. Thus, the integration between research in linguistics and literature studies and teaching practice can contribute to an effective and critical knowledge. 


\section{REVISTA DA ABRALIN}

PALAVRAS-CHAVE

Literatura. Linguística. Ensino.

\section{KEYWORDS}

Literature. Linguistics. Teaching.

No Brasil, o curso de Letras aborda basicamente em sua grade curricular disciplinas nas áreas de Linguística e Literatura. Logo, infere-se que o profissional formado nessa área possui uma base elementar para uma possível abordagem de ensino interdisciplinar entre as áreas bases de sua formação. Entretanto, na prática, geralmente não vemos essa integração porque, dentre outras coisas, os cursos de Letras tratam de forma isolada os estudos linguísticos e literários e as pesquisas desenvolvidas nas universidades nem sempre chegam aos professores do ensino básico ou possuem reflexões ou propostas práticas para serem aplicadas em sala de aula.

Tendo em vista esse panorama, desenvolveu-se no evento Abralin ao Vivo (promovido pela Associação Brasileira de Linguística, com a colaboração de associações e sociedades internacionais de linguistas), a conferência intitulada Literatura, Linguística e Ensino, proferida por Marisa Lajolo, professora universitária, pesquisadora, crítica literária e autora de uma série de publicações fundamentais para o campo da pesquisa e ensino de literatura, dentre as quais destacam-se os livros Literatura: ontem, hoje, amanhã (LAJOLO, 2018) e A formação da leitura no Brasil (LAJOLO; ZILBERMAN, 2018), que baseiam a referida conferência, realizada no dia 20 de julho de 2020, disponível no Canal da Abralin no Youtube.

Em sua fala inicial, Lajolo apresenta dados recentes do Programa Internacional de Avaliação de Alunos (em inglês: Programme for International Student Assessment - PISA), coordenado pela Organização para a Cooperação e Desenvolvimento Econômico (OCDE) e organizado no Brasil pelo Instituto Nacional de Estudos e Pesquisas (INEP), para mostrar resultados atuais do desempenho em leitura de jovens brasileiros. A professora destaca que no ano de 2015 o Brasil estava em $59^{\circ}$ lugar entre 70 países avaliados, já no ano de 2018 a posição do país foi para $57^{\circ}$ entre os 79 países que constavam na avaliação.

Esses dados se juntam aos da produção e vendas do setor editorial brasileiro, com referências da Câmara Brasileira do Livro, com os quais a palestrante sinaliza que em 2018 foram produzidos no Brasil 350 milhões de exemplares de livros sendo, entre outros gêneros, 175 milhões de didáticos (o gênero mais editado no Brasil) e 68 milhões de exemplares religiosos. Considerando os 200 milhões de habitantes no Brasil no referido ano, seria em uma concepção idealista de que todos fossem leitores, 1.7 livros por habitantes. Além disso, a professora mostra que o predomínio desses dois gêneros se encontra também nos títulos, já que no mesmo ano, dos 46.828 títulos publicados, 10.726 eram títulos de didáticos e 6.451 eram de títulos religiosos. 


\section{REVISTA DA ABRALIN}

Os dados apresentados podem sugerir que a diminuição no número de exemplares e títulos produzidos no Brasil reflete na diminuição no número de leitores e estaria relacionada com a baixa avaliação em leitura que os jovens brasileiros possuem. No entanto, a autora propõe um questionamento sobre esses resultados: será que realmente as pessoas estão lendo menos ou apenas se avalia um tipo de leitura que não é mais predominante no Brasil? Essa reflexão é importante porque não podemos deixar de considerar que os recursos tecnológicos, inseridos em nossa sociedade, estão cada vez mais aproximando o ser humano de múltiplas formas de leitura, o que faz com que as pessoas de modo geral gastem mais tempo lendo em meios digitais, fato que não mudará em um futuro próximo, segundo Wolf (2019).

Lajolo continua sua fala mostrando que a falta de leitura que assola os brasileiros é antiga, a professora expõe dois trechos de textos midiáticos antigos. O primeiro, um artigo de Machado de Assis escrito para o jornal Diário do Rio de Janeiro em 1872, no qual o escritor critica o baixo número de publicações e leitura dos brasileiros e chama atenção para a apreciação do povo por leituras superficiais. O segundo, um excerto da Revista Brazileira, do século XIX, que mostra que a sociedade não estava preparada para consumir livros, o prestígio por esse objeto literário e a extrema valorização da leitura associada à falta de tempo para sua realização. Em contrapartida às publicações distantes de nosso tempo, mas próximas no que se refere ao conteúdo, Marisa Lajolo apresenta um trecho do ano de 2018 da coluna Opinião do jornal Edição do Brasil, que afirma que a prática de leitura ainda não está totalmente presente entre os brasileiros.

Diante dessas críticas que retratam a sociedade brasileira e sua relação com a leitura nos últimos séculos, Marisa Lajolo nos convida a refletir sobre nossa relação com a leitura atualmente, considerando que as práticas e os meios de leitura são distintos, os caracteres para a escrita e, consequentemente, a leitura deles nas populares redes sociais foi reduzida e a maioria das pessoas não tem paciência para ler um texto longo. Consoante a esse pensamento, Wolf (2019) alerta para o fato de que a leitura superficial e fragmentada, através de recursos digitais, pode dilapidar a capacidade humana de entender argumentos complexos, de realizar leitura crítica do que se lê e de ser capaz de considerar pontos de vista distintos.

Marisa Lajolo continua sua conferência abordando dados relativos aos cursos de Letras no Brasil. Ao todo, segundo o INEP, no ano de 2017 existia mais de 500 faculdades autorizadas a ofertar curso de Letras no país e, dentre elas, 1.589.400 alunos estavam matriculados na licenciatura, ou seja, projetavam a docência. Já na pós-graduação são 265 programas, sendo 150 mestrados, 105 doutorados e 10 mestrados profissionalizantes na área no ano de 2020. Considerando graduação e pósgraduação, a pesquisadora mostra qual seria a formação elementar desses alunos, levando em conta as perspectivas adotadas na área em todo o país. Em linguística, o foco é a Análise do Discurso e a perspectiva bakhtiniana, já em literatura os estudos estão centrados na Estética da Recepção e nos Estudos Culturais. Desse modo, a formação dos estudantes de Letras no Brasil está constituída sob essas perspectivas.

Para representar o desencontro entre essa formação em Letras, ancorada nessas concepções, e o que se ensina e se aprende nos ensinos fundamental e médio nas aulas de linguagens, Marisa Lajolo 


\section{REVISTA DA ABRALIN}

apresenta duas questões de português presentes nas salas de aulas brasileiras do ensino básico, a fim de exemplificar que a concepção de língua e literatura ensinada é fragmentada, resumida a nomenclaturas que não levam os alunos a um entendimento prático e que não apresentam perspectiva crítica. Tendo em vista essa realidade, percebe-se as contribuições que correntes teóricas como a Crítica Textual, a Análise do Discurso, entre outras, trazem para o ensino de língua e literatura em sala de aula (CARMAGNANI, 2002; GRIGOLETTO, 2002; CASTILHO, 2016; QUAREZEMIN, 2017; POSSENTI, 2017; SANTIAGO-ALMEIDA; MORANDINI; SILVA, 2018; entre outros).

Dessa maneira, com o objetivo de propor a integração entre Literatura, Linguística e Ensino, relacionando os conteúdos aprendidos nos cursos de Letras às práticas de ensino na educação básica, Lajolo apresenta como costuma fazer, como professora universitária, com os trabalhos finais (TCC, dissertação, tese) que seus alunos realizam. Todos eles são acompanhados de um texto de divulgação para professores em exercício no ensino básico e de uma atividade para o ensino fundamental e médio inspirada pela pesquisa desenvolvida.

Com essa proposta interdisciplinar podemos vislumbrar um caminho de união entre pesquisa e docência, ainda tão distante no Brasil. Divulgar projetos como este em eventos como o Abralin ao Vivo, no qual compartilha conhecimento sem fronteiras, é importante porque promove reflexões e interações positivas entre interessados no assunto do mundo inteiro. Assim, fica o convite aos estudantes de Letras e professores de língua portuguesa e literatura, além de todos os interessados em educação que assistam à conferência.

\section{REFERÊNCIAS}

CARMAGNANI, A. M. G. Por uma abordagem alternativa para o ensino de leitura: a utilização do jornal na sala de aula. In: CORACINI, M. J.(org.) O jogo discursivo na aula de leitura. Campinas: Pontes, 2002.

CASTILHO, A. T. Prefácio. In: PIRES DE OLIVEIRA, R.; QUAREZEMIN, S. Gramáticas na escola. Petrópolis: Vozes, 2016, p.6-8.

GRIGOLETTO, M. A concepção de texto e de leitura do aluno de $1^{\circ}$ e $2^{\circ}$ Graus e o desenvolvimento da consciência crítica. In: CORACINI, M. J.(org.) O jogo discursivo na aula de leitura. Campinas: Pontes, 2002.

LAJOLO, M. Literatura: ontem, hoje, amanhã. São Paulo: Editora Unesp, 2018.

LAJOLO, M; ZILBERMAN, R. A formação da Leitura no Brasil. São Paulo: Editora Unesp, 2018.

LITERATURA, Linguística e Ensino. Conferência apresentada por Marisa Lajolo [s.l., s.n], 2020. 1 vídeo (2h 05min 40s). Publicado pelo canal da Associação Brasileira de Linguística. Disponível em https://www.youtube.com/watch?v=Ea7i79bu5C8\&t=1275s . Acesso em: 19 ago 2020.

POSSENTI, S. Linguistas na escola. Ciência Hoje, Coluna Palavreado, 2016. Disponível em: http://www.cienciahoje.org.br/noticia/v/ler/id/3088/n/linguistas_na_escola. Acesso em: 17 de agosto de 2020.

SANTIAGO-ALMEIDA, M. M.; MORANDINI, G. S.; SILVA, L. B. A. A crítica textual pula o muro da escola. Revista Linha D’Água (Online), São Paulo, v.31, n.2, p. 159-176, 2018. DOI: https://doi.org/10.11606/issn.2236-4242.v31i2p159176 


\section{REVISTA DA ABRALIN}

QUAREZEMIN, S. Ensinar Linguística na Escola: um encontro com a realidade. Working Papers em Linguística, v. 18, n.2, p.69-92, 2017.

WOLF, Maryanne. O cérebro no mundo digital: os desafios da leitura na nossa era. São Paulo: Editora Contexto, 2019. 